\title{
Nutrition security is more than food security
}

To the Editor - One of the great human achievements over the past half century is that, on a global basis, advances in food production have largely kept pace with demand. Today, more than 6 billion people are not hungry, up from about 2 billion 50 years ago. But we should not be complacent. Despite these successes, more than 820 million people are still hungry ${ }^{1}$ and at least 2 billion more lack sufficient nutrients ${ }^{2}$; paradoxically, there are also already more than 2 billion people who are overweight or obese ${ }^{2}$. This triple burden of malnutrition has been noted as the 'new normal'3 (and remember that 'malnutrition' means bad nutrition, not only under-nutrition).

For some time the 'food' debate centred on food security, drawing on widely accepted thinking from the 1996 World Food Summit ${ }^{4,5}$ which defined food security as a state or condition "when all people, at all times, have physical, economic and social access to sufficient, safe and nutritious food to meet their dietary needs and food preferences for an active and healthy life". When originally drafted, the emphasis was on averting hunger, which meant focussing on energy calories. However, the inclusion of the adjective 'nutritious' signalled that food also needs to contain sufficient nutrients - nutrients are a necessary contributor to food security.

More recently, as the nature and severity of under-nutrition, especially stunting and wasting in children, has become more apparent, the nutrition community has developed the notion of food security to underline quality and also to include environmental factors. In their 2012 report $^{6}$, the Committee for World Food Security set the benchmark as "when all people, at all times, have physical, social and economic access to food which is safe and consumed in sufficient quantity and quality to meet their dietary needs and food preferences, and is supported by an environment of adequate sanitation, health services and care, allowing for a healthy and active life". Food per se is thus only one factor contributing to nutrition security.

Even more recently, concerns have been growing over the third aspect of malnutrition: overweight and obesity. This is due, mainly, to the over-consumption of energy-dense foods (and especially 'empty' calories) but also to other factors, such as insufficient exercise and genetics. Together, these lead to diet-related diseases such as type 2 diabetes and cardiovascular disease.

So how does differentiation of the words 'nutrients', 'nutritious' and 'nutrition security' help address the 'new normal' challenge of the triple burden of malnutrition? First, we should be clear about what each word means: 'nutrient' is a constituent; 'nutritious' is a descriptor; 'nutrition' is a state or condition. Second, we should think about the ultimate goal of nutrition security rather than just food security. Although food intake might follow guidelines (aimed at achieving food security), intestinal parasites, for instance, can reduce nutrient uptake and thereby limit nutrient security. Thus, although the phrase 'food and nutrition security' is now often used, a better phrase would be simply 'nutrition security': nutrition security encompasses food security, which encompasses nutrient content.

Finally, while noting that nutrition security pertains to the individual, we must recognise that there are multiple factors that influence how we achieve it - and the responsibility for taking action spans jurisdictional levels ${ }^{7}$ from the community, to the nation, to the world.

John Ingram

Environmental Change Institute, University of

Oxford, Oxford, UK.

e-mail: john.ingram@eci.ox.ac.uk

Published online: 13 January 2020

https://doi.org/10.1038/s43016-019-0002-4

References

1. FAO, IFAD, UNICEF, WFP \& WHO. The state of food security and nutrition in the world 2017. Building resilience for peace and food security (FAO, 2017).

2. Fanzo, J. et al. 2018 Global Nutrition Report: Shining a light to spur action on nutrition (Global Nutrition Report, 2018).

3. Haddad, L. et al. J. Nutrition 145, 663-671 (2015).

4. FAO Report of the World Food Summit (FAO, 1996).

5. FAO, WFP \& IFAD. The state of food insecurity in the world: economic growth is necessary but not sufficient to accelerate reduction of hunger and malnutrition (FAO, 2012).

6. CFS. Global strategic framework for food security and nutrition 41-42 (FAO, 2012).

7. Cash, D. W. et al. Ecol. Soc. 11, 8 (2006).

Competing interests

The authors declare no competing interests. 